
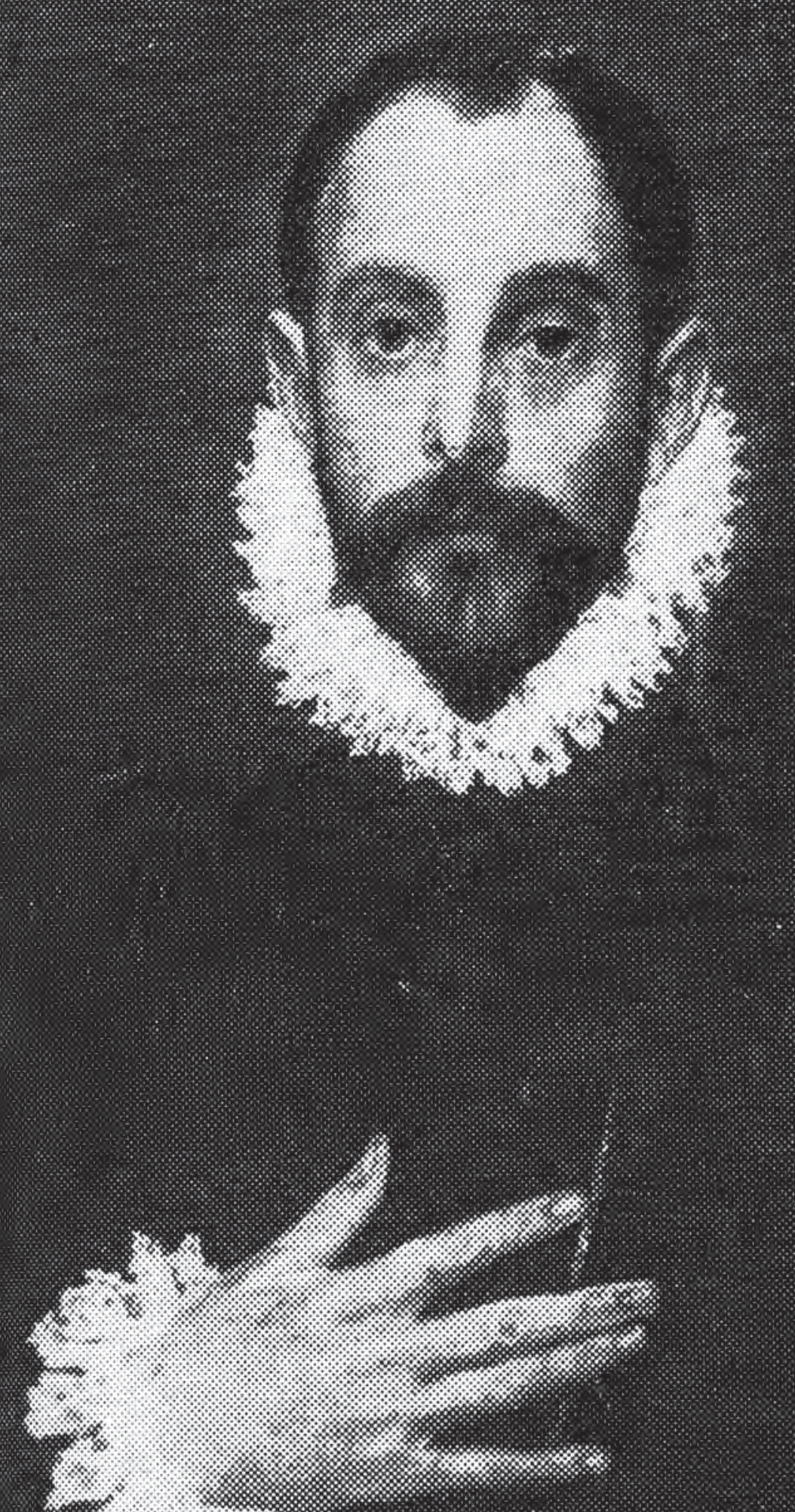


\title{
AS DOBRADURAS DA CIDADE
}

\author{
A CIDADE NAS FRONTEIRAS DO LEGAL E ILEGAL. \\ Telles, Vera da Silva. Belo Horizonte: Argvmentvm, 2010, p. 276.
}

DANIEL DE LUCCA

[1] Deleuze, Gilles. Adobra:Liebnize o Barroco. Campinas: Papirus, 1991; Deleuze, G. Foucault. São Paulo: Brasiliense, 2005 .
Em seus escritos sobre Michel Foucault e Gottfried Leibniz, Gilles Deleuze forjou e utilizou-se do conceito de dobra (plis). . Segundo Deleuze, tudo no mundo existe dobrado. Avida, ela mesma, seria uma dobra aberta, permanentemente inacabada e cuja flexão ao fora e ao dentro remeteria a um tipo de movimento que implica e multiplica, conecta e separa, dividindo-se infinitesimalmente em outras dobras menores e maiores, mas conservando sempre uma coesão que é própria de sua articulação. De Leibniz, Deleuze também tira a metáfora da cidade como um labirinto do contínuo: passagens e bloqueios, pedaços daqui que se encontram acolá, contornamentos, reviravoltas, mil dobras. Se essa cidade-labirinto pode ser de fato imaginada como o evento do origami, cuja arte dobra, desdobra e redobra infinitamente a superfície de sua trama, então a São Paulo que emerge do trabalho de Vera da Silva Telles parece ser uma espécie de experimentação radical desse pensamento.

Resultado de dez anos de diálogos, reflexões e inflexões de pesquisa, Acidade nasfronteiras do legale ilegal apresenta e descreve de perto uma São Paulo em certos aspectos inusitada. O mundo urbano aparece ali precisamente no cruzamento cerrado de inúmeros vetores de transformações: no mundo do trabalho e suas relações; nos novos circuitos da economia informal urbana; na globalização e no ultraliberalismo dos mercados metropolitanos; na reconfiguração do Estado e dos serviços públicos; na proliferação das ONGs, associações e outros dispositivos gestionários diante da "nova questão social"; no surgimento de micromecanismos de regulação local dos conflitos cotidianos e nas implicações e figurações do crime e da violência. A articulação entre os problemas empíricos, a multiplicidade de conceitos e referenciais teóricos e as inúmeras questões de ordem metodológica impressionam 
o leitor desavisado e traduzem a densidade e a pluralidade do pensamento de uma autora que tem sido referência obrigatória nos estudos sobre a dinâmica urbana paulistana.

O livro, produto de sua livre-docência defendida no departamento de sociologia da Universidade de São Paulo no final de 2010, é fruto de um intercâmbio mais amplo com pesquisadores estrangeiros e brasileiros, destacando-se aí o papel fundamental da equipe de jovens pesquisadores que, sob sua orientação, se voltaram para as diversas facetas na qual as mutações da cidade poderiam serflagradas, descritas e analisadas. Dividida em duas partes, a organização da obra reflete um duplo momento de reflexão da pesquisa. A primeira parte, intitulada "Experimentações", expressa uma fase inicial das investigações que contou com a parceria de Robert Cabanes e resultou na publicação, em 2006, de um livro organizado por ambos os autores ${ }^{2}$, a partir de um conjunto de pesquisas coletivas do qual originam os três primeiros capítulos da obra aqui discutida. Já a segunda parte, "Deslocando o ponto da crítica", aponta para o esforço de colocar a situação urbana paulistana num jogo mais ampliado de referências, nacionais e internacionais, e para um aprofundamento maior das implicações empíricas, políticas e teóricas dos ilegalismos urbanos.

De fato, o trabalho enfrenta um dos maiores desafios colocados para os estudos urbanos hoje: articular coerentemente conceitos que capturem processos, mecanismos, agências e diversas mediações capazes de apreender a heterogeneidade, a fragmentação e a polarização social da metrópole contemporânea. Diferente dos estudos que tomam a cidade apenas como paisagem ou pano de fundo dos processos analisados, ou mesmo daquelas pesquisas que a focam como principal realidade a ser interrogada, há um empenho geral em cruzar diferentes instâncias de análise e distintos setores de atividade urbana em prol de um diagrama de inteligibilidade transversal, mas sempre situado no tempo e no espaço. Com isso, aquilo queé lançado ao primeiro planoé justamente o trabalho instersticial dos conectores, mediadores, tradutores, passadores, em suma, os operadores das dobras que permitem jogar com o mundo urbano e seus múltiplos campos de gravitação. Desse modo, a cidade e seus problemas, ou melhor, "a questão urbana", não é tratada numa definição prévia e modelar, mas como diz Telles "é figurada no andamento mesmo das prospecções como questão (parcial) e interrogações (sempre reabertas)"3.

Se o conjunto da obra tem como principal eixo de articulação justamente esta transitividade entre diversos territórios, universos de códigos e circuitos de práticas, é nas fronteiras do legal e ilegal, como diz o título, que toda argumentação analítica e empírica centra fogo. A principal referência teórica aqui é Michel Foucault e seu conceito de "gestão diferencial dos ilegalismos", conceito que diz respeito a um
[2] Telles, V. da S. e Cabanes, R. (orgs.). Nas tramas da cidade: trajetórias urbanas e seus territórios. São Paulo: Humanitas, 2006. 
[4] Foucault, M.Vigiar e punir: nascimento da prisão. Petrópolis: Vozes, 2001, p. 226.

[5] Das, Veena. "The Signature of the State: The Paradox of Illegibility". In: Life and Words: violence and the descent into the ordinary. Berkeley/Los Angeles: University California Press, 2007.

[6] Telles, V.da S., op.cit., p. 10.

[7] Foucault, M. "Gerir os ilegalismos”. In: Pol-Droit, Roger (org.). Foucault entrevistas. São Paulo: Graal, 2006, pp. 50-51. conjunto de práticas de diferenciação, tipificação e hierarquização ativadas por dispositivos que cristalizam, fixam suas formas e "tendem a organizar a transgressão das leis numa tática geral de sujeição"4. Longe de desconsiderar os efeitos materiais e políticos da lei, busca-se compreender que o exercício de sua letra, "a assinatura do Estado" como diz Veena Das 5 , instaura campos de força e de conflito, estabelecendo todo um jogo de posições "numa espécie de tabuleiro de xadrez, com casas controladas e casas livres, casas proibidas e casas toleradas, casas permitidas a uns, proibidas a outros". Disso, conclui-se, "numa formulação bem brasileira" 6 , como lembra Angelina Peralva no prefácio do livro, que "a lei não é feita para impedir tal ou tal tipo de comportamento, mas para diferenciar as maneiras de burlar a própria lei"7.

A obra persegue, assim, esses "torneios da lei", dobraduras que articulam não só o legal e o ilegal, mas também o lícito e o ilícito, o formal e o informal. $\mathrm{O}$ foco nos ilegalismos e nos jogos de poder disputados em suas fronteiras, como explica a autora, busca lançar luz sobre uma inquietante linha de sombra que perpassa a experiência metropolitana em suas dimensões mais cotidianas e corriqueiras. E aí reside uma poderosa hipótese: a de que a vida urbana é atravessada, e em boa medida estruturada, por uma crescente teia de ilegalismos - novos, velhos e redefinidos - dispersa nas práticas e nos fluxos urbanos, os mais variados, assim como os mais prosaicos.

Um caso analisado no capítulo 5 ("Nas dobras do legal e ilegal: ilegalismos e jogos de poder") é ilustrativo. Doralice, 40 anos, moradora de um bairro da periferia paulistana, trabalha como diarista e também faz e vende pães e doces para complementar a renda de sua extensa família. Mulher batalhadora, Doralice "não hesita quando surge a oportunidade de montar uma banca de CDs piratas em um bairro próximo à sua casa", acionando com isso uma cascata de relações com intermediários: os "garotos de uma favela ao lado chamados para garantir a venda durante o dia, enquanto ela sai para o trabalho de diarista"; o agenciador dos CDs e o laboratório em que os CDs são copiados e distribuídos; os fiscais e os policiais aos quais os vendedores de rua têm de pagar pela proteção, ou melhor, pela extorsão. Entre essas relações mobilizadas como forma de lidar com as necessidades da vida, Doralice também se enreda numa "espantosa rede que opera o mercado de receitas médicas fraudadas para conseguir o remédio de que depende a vida do marido", e acaba transformando-se, vez ou outra, na própria intermediária desse mercado negro. Mais à frente, 'Doralice não encontra nenhuma razão moral para recusar o 'serviço' quelheé proposto por um conhecido próximo e de confiança, e colocar a encomenda de 'farinha' em sua bolsa, entrar no ônibus, atravessar a cidade e tranquilamente levar a mercadoria a seu destino, trazendo de volta um ganho modesto, mas que fará toda a diferença no orçamento 


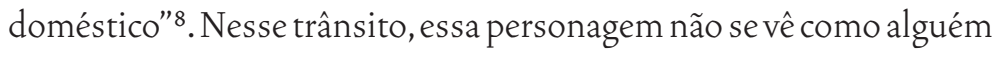
comprometido com o "mundo do crime" ou com práticas imorais, mas como alguém que está se virando do jeito que pode através de "bicos" aqui e acolá.

A história de Doralice não é excepcional, é uma entre outras, "a vida de uma mulher infame" diria Foucault ${ }^{9}$, uma história minúscula que permite entrever a complicada cadeia de mediações e relações de poder que conectam e situam os sujeitos na trama concreta de suas existências. São então os traçados dessas "mobilidades laterais", como conceitua Telles, que permitem explorar essa zona cinzenta na qual a cidade cotidianamente é dobrada e virada pelo avesso em suas normas, códigos e regulamentações formais. A cuidadosa análise das trajetórias urbanas - resultado, entre outras coisas, da proximidade com o trabalho de Robert Cabanes e seus estudos sobre o método biográfico $^{10}$ - emerge como perspectiva capaz de enfrentar e redesenhar as dicotomias e binaridades clássicas presentes em boa parte dos estudos sobre cidade e segregação urbana: trabalho e moradia; produção e reprodução social; exploração do trabalho e espoliação urbana; centro e periferia; riqueza e pobreza; e, como não poderia deixar de ser, a cidade legal e a cidade ilegal. No livro, esses pares conceituais não são propriamente abandonados, mas permanentemente problematizados, recolocados e dobrados uns nos outros, no movimento mesmo das descrições etnográficas que acompanham e fornecem o solo no qual a análise se desenrola.

Do ponto de vista metodológico, é de fato notável como o foco nas mobilidades e nos regimes de circulação, com seus bloqueios, desvios e formas de acesso contrapõe e desloca a imagem da cidade partida ${ }^{11}$ ou da cidade de muros $^{12}$, para outra que reside nas tramas da cidade ${ }^{13}$ e que preenche justamente o "entre" dos espaços fronteiriços. Contudo, longe de negar a existência de dispositivos de controle, barragem ou mesmo contenção na cidade, a análise buscou atentar para o fato de que as fortificações e os cercos da vida urbana são, todos eles, muito mais prenhes de fissuras e porosidades do que se imagina. Não partindo das partes separadas e extremadas que supostamente comporiam uma cidade dual, mas voltando-se para a própria relação que instaura ou contesta o movimento da divisão, o livro de Telles problematiza o próprio trabalho de dobradura que a experiência urbana opera sobre si mesma, evidenciando no jogo dessas fronteiras as zonas de turbulência e de intensa negociação que ainda precisam ser mais bem entendidas, mas que da ótica de seus atravessadores e passadores ordinários não são tão excepcionais assim.

No entanto, o problema da mobilidade urbana nãoé novo. Influenciado pelos trabalhos de Georg Simmel e seu personagem conceitual do "estrangeiro" (stranger), como um ser ao mesmo tempo múltiplo e
[8] Telles,V.da S., op.cit., pp.173-75.

[9] Foucault, M. “Avida dos homens infames". In: Ditos \& Escritos IV. Rio de Janeiro: Forense Universitária, 2003.

[10] Cabanes, R. Travail, famille, mondialisation. Récits de la vie ouvrière. São Paulo: IRD/Karthala, 2002.

\footnotetext{
[11] Ventura, Zuenir. A cidade partida. São Paulo: Companhia das Letras, 1994.

[12] Caldeira, Teresa. Cidade de muros: crime, segregação e cidadania em São Paulo. São Paulo: EDUSP, 2003.

[13] Telles, V. da S. e Cabanes, R., op.cit.
} 
[14] Grafmayer, Yves e Joseph, Isaac (orgs.). L'Ecole de Chicago: Nassaince de l'ecologie urbaine. Paris: AubierMontaigne, 1994.

[15] Alsayyad, Nezar e Roy, Ananya. "Modernidade medieval: cidadania e urbanismo na era global". Novos estudos Cebrap, $\mathrm{n}^{\circ} 85,2009$.

[16] Freire, Carlos.Trabalho informale redes de subcontratação. São Paulo: dissertação de mestrado, $\mathrm{FFLCH}_{-}$ USP, 2008.

[17] Sciré, Claudia. Consumo popular, fluxos globais: práticas, articulações e artefatos na interface entre a pobreza e a riqueza. São Paulo: dissertação de mestrado, FFLCH-USP, 2009. móvel, interno e externo aos agrupamentos, os estudos da Escola de Chicago inauguraram um novo modo de analisar a cidade. A cidade vista através do movimento de seus habitantes, através de seus conflitos, de seus deslocamentos e seus modos de territorialização' ${ }^{14}$. Mas se na passagem para o século xx a experiência de pesquisa em Chicago sobre as histórias de vida, as trajetórias habitacionais e ocupacionais, associava diretamente entre si os fenômenos de migração, urbanização, industrialização e modernização, hoje, cem anos depois, as questões colocadas pelos estudos de mobilidade são de outra ordem e outra escala. Se os fenômenos de ecologia urbana eram montados com relação ao problema das nacionalidades e da integração nacional americana — assim como os estudos urbanos brasileiros dos anos 1970 e 1980 tinham como questão de fundo o processo de modernização (sempre incompleta) de nosso país - após os anos 1990, com a abertura dos mercados aos capitais e demais fluxos transnacionais que pousam e decolam em velocidade nas grandes metrópoles, iria se tratar de uma análise ecológica muito mais ligada à globalização e seus territórios ${ }^{15}$.

Esse é outro importante eixo de inflexão do livro. Ao demonstrar como o crescimento do mercado informal está diretamente conectado aos circuitos de um novo capitalismo mundializado, opera-se aqui mais uma dobra, de modo que a reluzente e pujante economia global é colocada face a face com o mundo ordinário das reciprocidades populares, estendendo e complexificando mais ainda as relações entre riqueza e pobreza urbana. E as etnografias de sua equipe de pesquisadores flagram bem esse processo. Como revela o trabalho de Carlos Freire ${ }^{16}$ sobre os circuitos urbanos do comércio informal que mobilizam o "trabalho sem forma", conectando contrabando e pirataria e estabelecendo poderosas articulações entre o informal e os circuitos ilegais das economias transnacionais. Aqui, as vagas migratórias também são outras, não mais aquelas que buscam necessariamente a instalação durável e a inserção permanente numa sociedade hospedeira. São trabalhadores muito mais flexíveis, conectados e circulantes, bolivianos operando na indústria de confecção paulistana, articulados e agenciados, por sua vez, pelos comerciantes coreanos que controlam o nicho do tecido sintético na cidade.

Como também mostra a pesquisa de Claudia Scirée ${ }^{17}$, a economia doméstica é toda redefinida em função das condições de acesso aos grandes equipamentos de consumo, shopping centers, Casas Bahia e feirinhas das mais variadas que, com uma literal "financeirização da pobreza" decorrente da explosão do consumo popular e a generalização dos cartões de crédito, alteram a organização familiar, as sociabilidades vicinais e as práticas de lazer locais. Nesses circuitos de troca e dádiva, entrecruzam-se, mais e mais, lógicas da dívida onde se compra hoje para se pagar apenas quando puder. Os contratos de troca extra- 
polam a palavra empenhada e se formalizam em documentos jurídicos implicados também em juros variáveis e variantes. São práticas de endividamento sucessivo que enredam parentes e amigos na financeirização do velho "fiado" e que, entre os empréstimos que vão para lá e para cá, prorrogam sempre mais o momento de pagamento, podendo levar a gestão da dívida, sua negociação, ao infinito.

O capítulo final do livro, o único totalmente inédito, toca no centro nervoso das discussões a respeito deste fantasma que ronda a metrópole e que é chamado, no singular, de "violência urbana". Em torno da impressionante queda na taxa de homicídios que se deu em São Paulo a partir dos anos 2000 , Telles mostra como se montou um verdadeiro campo de disputas e controvérsias no qual argumentos políticos, estatísticos, sociológicos e etnográficos se cruzam e se confrontam na busca pela explicação do acontecimento e na legitimação dos discursos em pauta. Entre as hipóteses dispostas nesse debate destaca-se aquela que, celebrada pelo próprio governo do estado de São Paulo, explica a baixa no índice dos assassinatos como resultado da eficiência das políticas de segurança pública. Também a "hipótese PCC" circula nessa discussão apoiada na ideia de que a hegemonia da facção no comércio das drogas teria contribuído para a "pacificação" de territórios conflagrados mediante expedientes como os "debates". Chamados também de "forinhos", os "debates" são uma espécie de tribunal em que as partes envolvidas são chamadas para dar sua palavra, com a participação dos patrões da biqueira e a intermediação de "irmãos" do "partido", seja presencialmente ou através de celulares. Nas palavras da autora:

No início, mecanismos postos em prática na resolução das desavenças internas aos "negócios do crime" è̀s organizações criminosas. Surge, primeiro no universo carcerário e transborda, depois, para os bairros da periferia da cidade e, em pouco tempo, passa a ser acionado para a regulação de microconflitos cotidianos: de brigas de vizinhos a disputas em torno da distribuição de lotes em áreas de ocupação de terra, passando por problemas com adolescentes abusados, pequenos delitos locais, brigas de marido e mulhere miríades de situações próprias da vida nesses bairros ${ }^{18}$.

Com isso aprendemos que, entre a prisão e o bairro, não só pessoas e coisas circulam, mas também valores e modos de agir, procedimentos e "debates" fluem pelos inúmeros "vasos comunicantes" que conectam o dentro e o fora da cadeia ${ }^{19}$. Dialogando com estudos recentes e amparada por um trabalho de campo de longa duração com Daniel Hirata ${ }^{20}$ - pesquisador cuja interlocução nesse ponto é de fundamental importância na argumentação da autora - , Telles coloca em evidência as formas territorializadas de regulação extralegal da vida (e também da morte) e explora as continuidades e as descontinui-
[18] Telles, V. da S., op.cit., p. 208.

[19] Godoi, Rafael. “Prisão, periferia e seus vasos comunicantes em tempos de encarceramento em massa". Texto apresentado no seminário Crime, violência e cidade. São Paulo: FFLCH-USP, 2009 .

[20]Hirata, Daniel. Sobreviver na adversidade: entre o mercado e a vida. São Paulo: tese de doutorado, FFLCHUSP, 2010. 
[21] Telles, V. da S.Direitos sociais: afinal do que se trata? Belo Horizonte: Editora UFMG, 1999; Telles, V. da S. Pobreza e cidadania. São Paulo: Editora 34, 2001.

[22] Oliveira, Francisco de e Rizek, Cibele Saliba (orgs.).A era da indeterminação. São Paulo: Boitempo, 2007.

[23] Telles, V.da S., op. cit., p.17o. dades desses diferentes mecanismos de gestão através da recuperação da história urbana local e seus principais personagens. Com isso, "justiceiros", "matadores" e "traficantes" aparecem como marcadores temporais de diferentes regimes de poder numa cronologia da violência que se estende por trinta anos no passado. A variação de escala e a mudança de perspectiva, operada em prol das "histórias minúsculas" desses personagens, com efeito, dissolve o espectro monstruoso e abstrato da "violência urbana" e, entre outras coisas, revela como as "mortes matadas" ocorrem, também, por motivos os mais corriqueiros, comuns e demasiadamente humanos possíveis: traições, mal-entendidos, brigas, pendências, vinganças, acertos de conta.

O livro termina com este aprofundamento crítico a respeito dos jogos de vida e morte na cidade de São Paulo, seus jogadores, percursos e cenas de atuação, questões muito diferentes de suas pesquisas anteriores, que tematizavam centralmente a pobreza, a cidadania e suas relações ${ }^{21}$. A trajetória de pesquisa de Vera Telles desenha, de fato, um importante deslocamento nos campos de problematização que efetua e que pode ser parcialmente flagrado em seus aspectos teóricos no capítulo 4 do livro ("Tramas da cidade: fronteiras incertas do informal, ilegal, ilícito"), em que, num debate mais amplo travado com seus interlocutores do CENEDIC (Centro de Estudos dos Direitos da Cidadania ${ }^{22}$, interroga-se a respeito dos limites da linguagem dos direitos e da implosão de seu vocabulário conceitual: leis, cidadania, participação e espaço público.

Situado no meio do livro, o capítulo constitui uma espécie de dobradiça articulando as duas metades da obra e permite compreender melhor as reviravoltas de uma pesquisadora que, vinte anos atrás, tinha como principal referência Claude Lefort e Hannah Arendt (e os problemas da "invenção democrática" e da "revolução"), e hoje trabalha sob um diagrama de análise montado a partir de Michel Foucault e Giorgio Agamben (e a própria reconceituação da política referente ao "biopoder" e à "governamentalidade", à "vida nua" e ao "estado de exceção").

Perguntávamos, e era a pergunta que eu própria fazia quando lidava comessas realidades:quais as potências que permitem transformaro "pobre" (personagem) em "cidadão" (outro personagem)? Pois, agora, a pergunta é outra. A pergunta que esses personagens estão nos sugerindo é: como escapar da morte matada ou da infelicidade do pobre coitado?23

Mas a retórica do "desmanche" e da "era da indeterminação", utilizada para caracterizar essa transformação da política em pura administração das urgências e gestão dos riscos, não funciona, tal qual se poderia imaginar, como um paralisante do pensamento e da ação. 
Muito pelo contrário, a incerteza de nossa atualidade emerge no livro como o principal propulsor do esforço em descrever este mundo em mudança. Não por acaso, todo o corpo da obra é organizado em função desta experimentação de forte teor etnográfico: "experimentação como prática de pesquisa, como forma de produção de conhecimento, também como experiência de pensamento" (p.11).

Transversal às escolas e às tradições nacionais, seja na interlocução de longa data com a literatura sociológica brasileira (Lúcio Kowarick, Chico de Oliveira, Cibele Rizek) ou na problematização da cidade através de referenciais franceses ainda pouco conhecidos em nosso país (Marcel Roncayolo, Bernard Lepetit, Isaac Joseph, Yves Grafmeyer), destaca-se no trabalho um notável diálogo com o pensamento antropológico (Arjun Appadurai, Veena Das, George Marcus, Paul Rabinow, Bruno Latour, Ulf Hannerz, Michel Agier, Alain Tarrius, Alba Zaluar). Ainda que difuso, esse diálogo aparece aqui e ali em todo corpo da obra e ajuda a estabelecer o fio condutor no qual o parâmetro descritivo da pesquisa se desdobra no próprio parâmetro da crítica. Seja como for, talvez fosse interessante operar aí uma outra dobra, não destacada no livro e que seria ao mesmo tempo um aprofundamento desse diálogo com a antropologia. Uma dobra capaz de vergar a pesquisa sobre si mesma, fazendo-a refletir mais detidamente sobre as condições de investigação quando o campo é "minado" e marcado pela desconfiança e pelo medo. O que, por sua vez, permitiria introduzir a própria urgência no coração (não só da política, mas também) do trabalho etnográfico.

O leitor que se dedica a pesquisas em paisagens análogas definitivamente fica muito instigado em saber mais sobre a "cozinha" do trabalho de investigação: como se deu a entrada em campo, quais os parâmetros metodológicos que orientaram a seleção dos entrevistados, quais foram os contextos de enunciação das narrativas registradas; e também sobre a tessitura das relações estabelecidas entre os objetos e os sujeitos da investigação, especialmente quando esta, como é o caso, se desenrola num tempo de longa duração. Além destas, outras questões podem ser levantadas. O que significa, de fato, pesquisar em territórios de exceção? Quais condições de trabalho e de conhecimento se impõem ao pesquisador nessas zonas de turbulência e indeterminação? Como pensar sobre o conflito e a violência quando se está fazendo pesquisa no centro desses processos? Como teorizar sobre a localização desses saberes?

Essas e inúmeras outras perguntas afloram da leitura do vigoroso trabalho de Vera Telles. E é justamente pela multiplicidade de problemas abertos, conceitos apresentados, hipóteses levantadas, também pela impressionante quantidade e qualidade de informações sobre São Paulo, que $A$ cidade nas fronteiras do legal e ilegal é uma formidável "caixa de ferramentas" para pesquisadores da área e um manancial de 
conhecimento para todos aqueles que se interessam em decifrar a cidade numa perspectiva que transcenda o já dito. Essa obra de fôlego, que nos apresenta uma São Paulo em processo e feitura, e por isso mesmo incerta e desconcertante, desenha uma paisagem urbana onde tudo pode se relacionar com tudo. Uma cidade feita de dobraduras na qual sempre existe uma dobra dentro da outra e na qual o maior perigo é perder-se na vertigem do embaralhamento promovido pelos inúmeros caminhos que a cidade-labirinto nos propõe.

DANiel De LuCCA é professor de Antropologia da Fundação Escola de Sociologia e Política de São Paulo e doutorando em Ciências Sociais na Unicamp. 